\title{
A Animação Stop Motion como atividade interdisciplinar em cursos de Design
}

\section{USING STOP-MOTION ANIMATION AS INTERDISCIPLINARY ACTIVITY IN DESIGN COURSES}

CRUZ, Gabriel F.S. ; Doutor em Design; Universidade Veiga de Almeida

prof.gabrielcruz@gmail.com

SOUZA, K. M. ; Doutora em Artes Visuais; Universidade Veiga de Almeida

katiasouza@uva.br

SPADA, D. ; Mestre em Psicanálise, Saúde e Sociedade; Universidade Veiga de Almeida

danielle.spada@uva.br

\section{Resumo}

Buscando refletir a natureza do Design como campo interdisciplinar, o presente artigo apresenta uma experiência colaborativa entre diversos cursos de Design em bacharelado e superior tecnológico utilizando como ferramenta a produção de animações em Stop Motion. Para isso algumas disciplinas dos cursos de Design de Interiores, Design Gráfico e Design de Moda da Universidade Veiga de Almeida trabalharam diversas etapas de forma integrada em um mesmo projeto, onde cada grupo de alunos, com sua determinada expertise, contribuiu para estender os limites disciplinares na realização de um projeto conjunto.

Palavras Chave: Ensino de Design; Interdisciplinaridade; Animação.

\section{Abstract}

This article presents a colaborative experience between diverse Design courses, using Stop-Motion animation technique, in order to demonstrate the very interdisciplinary nature of Design itself. Groups of students from Interior Design, Graphic Design and Fashion Design contributed to this experience using their own expertise in several steps, pushing the disciplinary limits in order to achieve a conjoint project.

Keywords: Design Learning; Interdisciplinarity; Animation. 


\section{Introdução}

O Design é por sua natureza interdisciplinar. Sua facilidade em adentrar por diversas áreas de conhecimento na resolução de problemas para as mais diversas situações o torna uma atividade extremamente versátil. Em muitas situações, na busca de soluções, o designer precisa adquirir conhecimentos mais aprofundados sobre o assunto que ele está abordando para que estas possam atingir o seu objetivo e a comunicação entre o cliente e seu público tenha sucesso.

Há [no design] implícita uma vocação interdisciplinar, pois se trata de uma área propícia para o trabalho conjunto com outras áreas de conhecimento. Uma das características de uma atividade de Design é o envolvimento de inúmeros conhecimentos de domínios distintos. Assim, não é raro encontrar-se um designer caminhando por áreas de conhecimentos que a princípio não lhe dizem respeito. (FONTOURA, 2011, p.91)

No entanto, é curioso notar que, mesmo começando esse artigo por uma frase que já é um jargão no meio acadêmico, o desafio de elaborar atividades interdisciplinares em cursos de design ainda representa, em muitos casos, um verdadeiro desafio para coordenadores, docentes e discentes.

Tal desafio aumenta quando se analisa que o Ensino no Brasil tendeu e tende a aumentar cada vez mais as habilitações específicas para os cursos de Design. Em seu marco inicial com a ESDI em 1961, o curso de Desenho Industrial, que adotava o padrão da escola alemã de Ulm formava apenas o profissional de Design sem nenhuma habilitação específica. Com o passar das décadas outros cursos de Design foram surgindo tentando se adequar as realidades e necessidades específicas da indústria brasileira, chegando a 16 cursos em 1976. Segundo Couto (2008, p. 24) um trabalho realizado pelo Conselho Federal de Educação que nomeou em 1978 uma comissão para gerar um novo currículo mínimo para os cursos de Design chegou apenas em 1987 ao parecer 02/87 que subdivida os cursos de Design em duas subáreas: Projeto de Produto e Programação Visual.

Após quase 20 anos, diversas mudanças e questões renovaram os cursos de Design: reformas educacionais, redes sociais, ecologia, mídias digitais, convívio online, etc.; o que levou à criação de cursos de Graduação Tecnológica, onde o Design vai trabalhar especificamente questões como Moda, Design de Interiores, Animação, Design de Jogos Eletrônicos, Audiovisual, entre outros.

Com a tendência de cursos mais específicos, surgem também disciplinas mais específicas possibilitando o aumento das barreiras entre as diversas subáreas do Design. Em alguns casos as especificidades da subárea são tão grandes que até mesmo surgem dificuldades dos estudantes de Design em reconhecer sua atividade de campo como Design. Em 2017, durante palestra organizada na Semana Internacional de Quadrinhos pela Escola de Comunicação da UFRJ, uma palestrante se apresentou dizendo que "era formada em Design, mas que não trabalhava com Design. " Apesar da formação em Comunicação Visual, trabalhar com quadrinhos e desenvolver cenários para séries de animação, não foram atividades reconhecidas formalmente pela ilustradora como sendo uma atividade no Campo do Design. Em outra situação, um professor do curso de Design Gráfico: Ilustração e Animação Digital, que forma Designers para trabalhar especificamente no campo da animação, resolveu desenvolver uma tarefa um pouco fora do escopo da disciplina, pois, como ele mesmo diz em sua tese:

Um dos fatores que levou à decisão de escolher o curso de Design Gráfico da Universidade Veiga de Almeida como campo foi o fato de, por ser uma graduação tecnológica, o curso possuir uma grade com grande carga de disciplinas práticas focadas em Animação e ilustração digital; cabendo às disciplinas otimizadas (comuns aos cursos da Escola de Design) 
a carga teórica e reflexiva sobre o Campo do Design. Com essa diferenciação entre esses dois tipos de disciplinas é comum encontrar alunos com dificuldade de entender a relação entre o conteúdo dessas com a parte prática do curso. (CRUZ, 2017, p. 66)

No contexto dos cursos diferenciados, visando desenvolver uma atividade realmente interdisciplinar, ajudando docentes e discentes a refletirem sobre o Design como campo dessa natureza será apresentado, neste artigo, a atividade desenvolvida durante o segundo semestre do ano de 2017 que contemplou, em um projeto interdisciplinar, a participação de 3 cursos: Superior Tecnológico em Design Gráfico: Ilustração e Animação Digital, Superior Tecnológico em Design de Interiores e Superior de Moda da Universidade Veiga de Almeida.

\section{Animação Stop Motion: Uma Proposta Interdisciplinar}

A proposta surgiu durante uma conversa entre os coordenadores dos cursos de Design de Interiores e Design Gráfico com uma professora que leciona em ambos os cursos sobre os processos de ensino aprendizagem que levam em consideração a interdisciplinaridade, e de que apesar de já possuir uma matriz curricular pensada com este objetivo, não havia um projeto que promovesse reflexões e ações conjuntas entre docentes e discentes. Uma inter-relação onde cada sujeito participante pudesse ser, ao mesmo tempo, ator e autor do processo e que, de fato, pudesse transformar a teoria em prática. Na maioria das vezes, mesmo em um currículo integrado, o trabalho dos docentes e discentes ainda permanece isolado. Mesmo com o incentivo aos estudantes para que seja desenvolvido um único projeto para mais de uma disciplina, eles mesmos não vislumbram esta possibilidade.

No experimento de uma ação interdisciplinar, o professor Gabriel Cruz, coordenador do curso de Design Gráfico, apresentou a possibilidade de trabalhar com os alunos da disciplina de Desenho e Animação Digital com o conteúdo de outra disciplina de primeiro período e lhe foi sugerido, pela professora Kátia Souza, trabalhar com os conteúdos de História da Arte. A partir deste momento, o projeto começou a delinear-se. Em sua configuração, sentiu-se a necessidade de unir as três habilitações em Design oferecidas pela instituição: Design de Interiores, Design Gráfico e Design de Moda.

Em uma reunião para o planejamento do projeto, o professor Gabriel expôs a necessidade de uma abordagem sobre Stop Motion, técnica de animação que não faz parte do conteúdo da disciplina de Desenho e Animação Digital e apresentou um livro sobre esta técnica, explicando-a e justificando sua importância para a formação discente. Durante este momento de reflexão a professora Katia, coordenadora do curso de Design de Interiores, falou que os alunos de seu curso poderiam fazer os cenários para serem usados nas animações em Stop Motion, já que precisam de cenários físicos. Neste contexto, a possibilidade de um projeto interdisciplinar estava realmente nascendo.

Apesar desta primeira reunião ter sido frutífera, o projeto ainda não estava constituído de forma interdisciplinar. A união de duas disciplinas de dois cursos constitui uma "multidisciplinaridade", o que, segundo Nicolescu et al. (2000), corresponde à busca da integração de conhecimentos por meio do estudo de um objeto de uma mesma e única disciplina ou por várias delas ao mesmo tempo. 
Pierre Delattre, que não diferencia multidisciplinaridade de pluridisciplinaridade, corrobora com Nicolescu ao afirmar:

Uma simples associação de disciplinas que concorrem para uma realização comum, mas sem que cada disciplina tenha que modificar significativamente a sua própria visão das coisas e dos próprios métodos [...]. Toda realização teórica que põe em prática saberes diversos corresponde de fato a um empreendimento pluridisciplinar (DELATTRE, 2006, p. 280).

Um projeto, para ser interdisciplinar, precisaria que cada disciplina fosse modificada durante seu andamento, promovendo uma unidade do saber. A partir disto, o pensamento estruturante do projeto se modificou e a preocupação com um fator de coesão entre diversos saberes foi elencado para ser o ponto de partida, fazendo com que cada disciplina pudesse abandonar sua própria especialidade e se construir em um novo campo além do seu próprio domínio, constituindo assim a interdisciplinaridade desejada. Hilton Japiassu e Danilo Marcondes (1993) definem o conceito interdisciplinaridade como:

Método de pesquisa e de ensino susceptível de fazer com que duas ou mais disciplinas interajam entre si, esta interação podendo ir da simples comunicação das ideias até a integração mútua dos conceitos, da epistemologia, da terminologia, da metodologia, dos procedimentos, dos dados e da organização da pesquisa (JAPIASSU; MARCONDES, 1993,p. 136).

Partindo dessas reflexões, uma nova reunião foi feita e novas disciplinas foram convidadas a participar do projeto, a fim de averiguar quais campos de saberes poderiam trabalhar juntos na constituição deste projeto. Em meio a reunião, definiu-se que o projeto seria uma animação em Stop Motion que envolveria desenvolvimento de bonecos para animação e seus figurinos, cenários, estrutura adequada para a filmagem e, por fim, a animação dos bonecos.

A professora Daniele Spada, da disciplina de Laboratório de Criação, que tem por objetivo desenvolver a capacidade criativa do aluno, sugeriu desenvolver os bonecos. O figurino ficou a cargo da disciplina "Processos Criativos em Moda". A estrutura para a animação, bem como os cenários foram assumidos pela disciplina de cenografia do curso de Design de Interiores. O roteiro seria elaborado pelos alunos de "Princípios de Animação". Ficando tudo organizado então da seguinte forma:

Quadro 1 - Definição das etapas do projeto Stop Motion

\begin{tabular}{lll}
\hline Objeto a ser desenvolvido & Animações em Stop Motion. & \\
$\begin{array}{lll}\text { Vídeos produzidos na técnica de animação em Stop Motion através de diversas disciplinas dos cursos da Escola } \\
\text { de Design. }\end{array}$ & Disciplina: & Curso de aderência: \\
\hline Etapa da animação: & Laboratório de Criação & Todos os cursos da Escola de Design \\
\hline Desenvolvimento dos personagens & Processos Criativos em Moda & Superior de Moda \\
\hline Desenvolvimento de Figurino & & Superior Tecnológico em Design de \\
\hline Desenvolvimento dos Cenários & Cenografia & Interiores \\
\hline
\end{tabular}


O projeto iniciou-se de forma interdisciplinar, onde cada disciplina se abriu para novas linguagens fora do seu domínio. A ideia inicial foi que, diante dos roteiros prontos, o projeto seria integrado em uma única história. A professora Daniele então sugeriu ao professor Gabriel, da disciplina de Princípios da Animação, o Festival do Minuto, com a proposta de fazer uma animação de 1 minuto.

Ao questionar a razão do tempo sugerido pela professora, o professor, que também é animador, recebeu como resposta que "1 minuto seria um tempo razoavelmente fácil". Isso demonstrou um pouco a diferença entre as percepções de um não animador e de um animador sobre a percepção do tempo em uma animação pois,

\begin{abstract}
Este exercício de observar, ouvir, analisar, processar e finalmente reconstruir e sintetizar as impressões em imagens cuidadosamente sequenciadas, constitui o dia a dia da vida de um animador. Este hábito diferenciado e esta entrega a contemplação propicia a percepção de uma realidade na qual um observador comum pode não se deter e nem valorizar da mesma Forma. (MAGALHÃES, 2015, p. 33)
\end{abstract}

Foi então assim que o professor de animação mostrou que realizar 1 minuto de animação em Stop Motion é muito dispendioso, pois é necessário construir cada momento da animação. Os movimentos que são realizados em milésimos de segundos, no Stop Motion são construídos e desconstruídos em sequência, sendo necessário manipular o boneco, a roupa do boneco, o cenário, a câmera, a luz, para fotografar uma única pose que faz parte de uma sequência de 24 imagens para gravar 1 segundo de animação. Todo este processo demandaria um tempo muito grande para se trabalhar com diferentes grupos de uma turma, isso só para falar da turma de Design Gráfico. Chegou-se então, a definição de que cada trabalho teria no máximo 10 segundos.

Definido o tempo, retornou-se a questão do roteiro, pois para 10 segundos não se poderia produzir um roteiro muito grande e este foi só o primeiro entrave do projeto. 0 mais interessante de todo este processo foi que este primeiro entrave aconteceu durante o desenvolvimento do projeto, em que os bonecos já estavam sendo pensados pela turma de Laboratório de Criação. Não havia muito tempo para discutir o projeto pois o semestre já havia começado e, mesmo assim, o grupo seguiu com o plano.

Até este momento, o que se tinha definido foi que o roteiro seria atribuição dos alunos de Design Gráfico, e que então viria a orientação para a confecção dos bonecos, figurinos e cenários. Mas, devido a este entrave no prazo, tudo teve que ser reelaborado: do roteiro à confecção de bonecos, cenários, peças e todos os elementos envolvidos.

Diante deste "cenário", a disciplina de Laboratório de Criação acabou por direcionar toda a produção, uma vez que ela mesma teve que repensar a sua atuação na produção dos bonecos. Sendo assim, o trabalho desenvolvido com a turma foi o de confeccionar um boneco/personagem que a princípio teria alguns atributos, mas não teria obrigatoriamente uma história. Neste sentido todos foram convidados e ler histórias infantis e, a partir destas histórias, criar um personagem. Este personagem teria algo que o identificasse, como um guerreiro, uma bruxa, uma criança, um herói, uma pessoa comum, uma fada, mas não teria uma história por detrás dele/a. Mesmo assim foi difícil 
trabalhar com os alunos nesta dinâmica pois todos ainda estavam construindo histórias para seus personagens.

As professoras da disciplina Laboratório de Criação, Daniele Spada e Luísa Tavares, pensaram em uma nova dinâmica que não ligassem as figuras a uma história, resolvendo então trabalhar com caricaturas, que nada mais é que exagerar características de cada pessoa e desta forma imprimir uma identidade que era o que os bonecos precisariam ter. Deste modo, cada aluno foi incentivado a trabalhar a sua própria caricatura e construir o seu próprio boneco. Esta identificação consigo mesmo motivou os alunos para o desenvolvimento dos bonecos. Algumas questões foram colocadas aos alunos como por exemplo a necessidade de articulação e sustentação dos bonecos. Portanto, era preciso pensar em materiais que cumprissem estas funções, mas sempre preservando a capacidade criativa de cada um.

Figuras 1 e 2 - Exemplos de estudos dos personagens em Laboratório de Criação

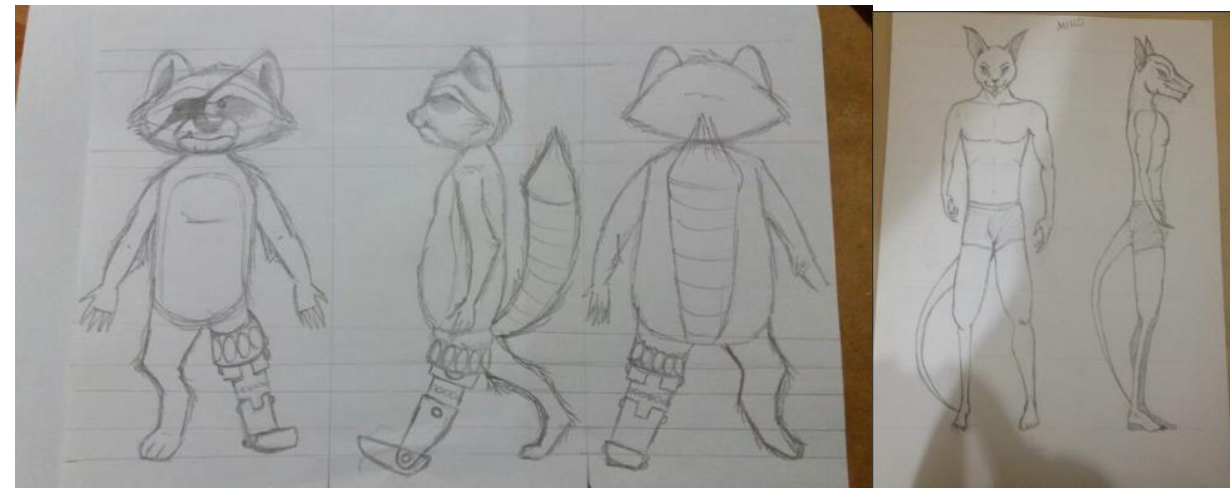

Fonte: os autores

Esta liberdade criativa também foi aplicada na disciplina de Processos Criativos em Moda para o desenvolvimento dos figurinos, já que os bonecos foram encaminhados às turmas de moda e eles também não seguiriam uma história pré-estabelecida, mas sim um perfil, uma personalidade que poderia ser trabalhada e desdobrada pelos professores da disciplina, permitindo que os alunos de moda também ficassem livres para compor seus figurinos.

Figuras 3 e 4 - Exemplos de Personagens finalizados com figurino

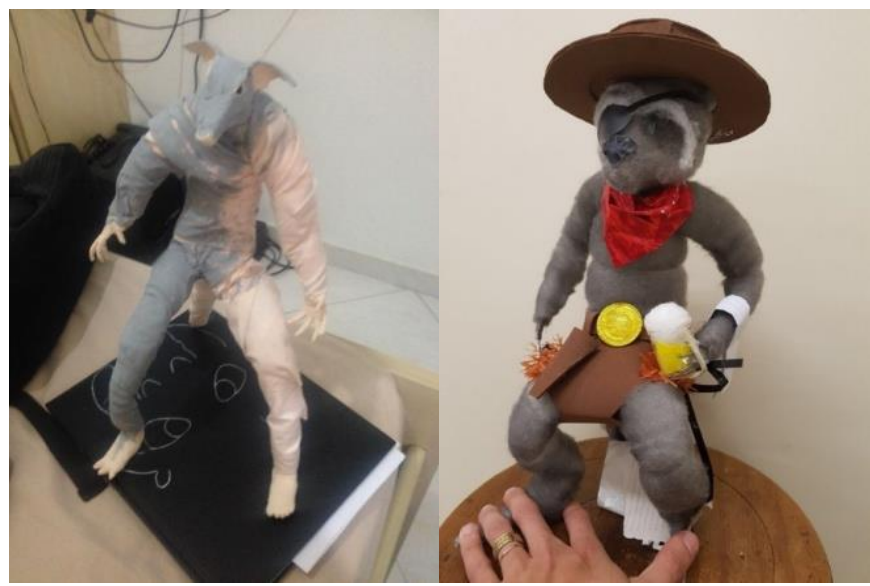

Fonte: os autores 
No desenvolvimento da cenografia o processo foi um pouco mais definido, mas também propiciou uma liberdade criativa. Para a elaboração da cenografia era necessário um norte, porém não tínhamos uma história. Então foi sorteado três perfis que já estavam sendo trabalhados tanto em Laboratório de Criação para desenvolver os bonecos, quanto em Processos Criativos em Moda para os figurinos, e destes três perfis foi então criado uma cena que representasse estes perfis, definindo tempo, espaço, lugar, atmosfera, criando então os cenários e adereços. Deste processo resultaram algo em torno de sete cenários com seus adereços que foram disponibilizados aos alunos que iriam produzir as animações.

Figuras 5 e 6 - Exemplos de Cenários

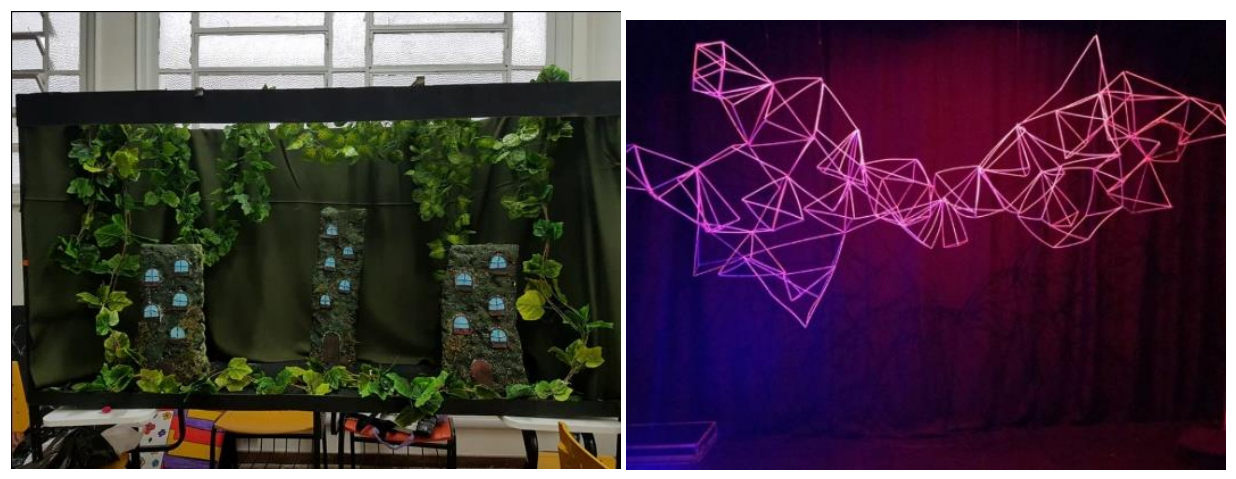

Fonte: os autores

Figuras 7 e 8 - Teste de personagens nos cenários

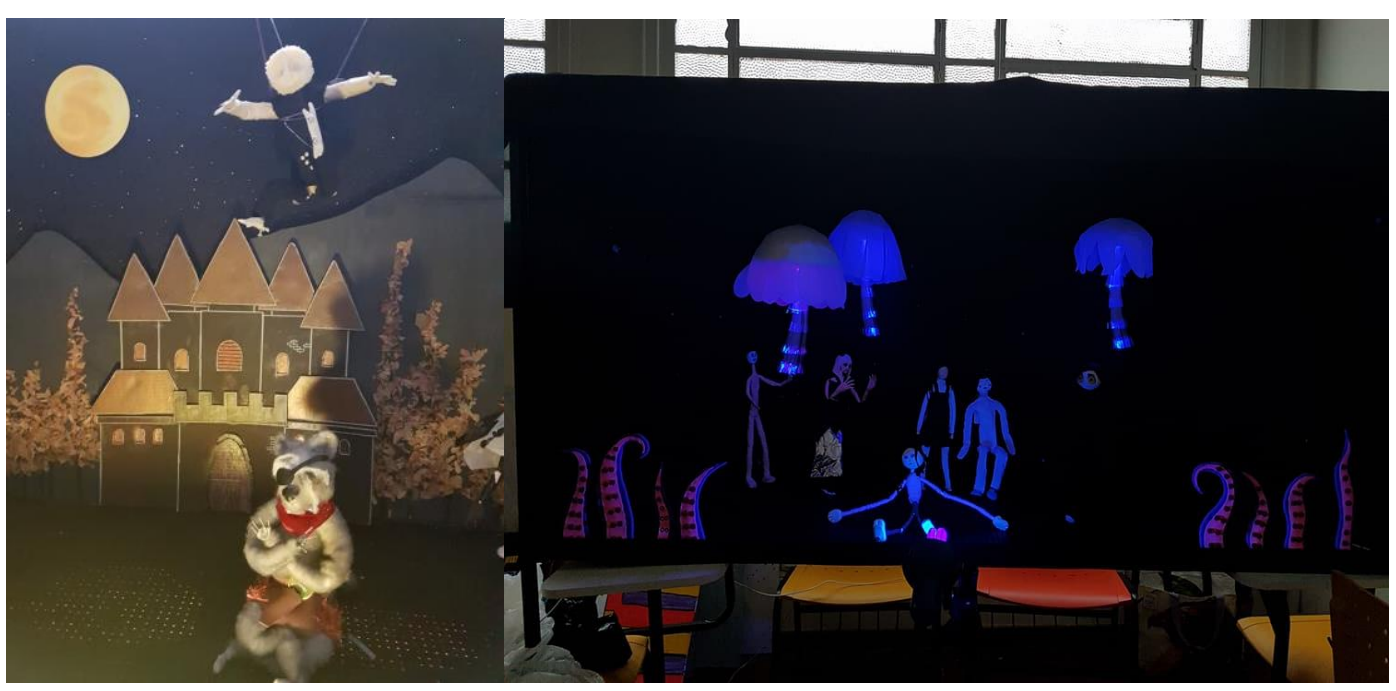

Fonte: os autores

Deste modo, o roteiro foi deixado para ser desenvolvido no momento da animação em que os alunos teriam uma diversidade de bonecos, cenários e adereços a partir dos quais o olhar de cada animador sobre estes objetos criaria, por fim, a história. Ao final do processo, reservamos uma sala durante uma semana onde foram colocadas duas estruturas de palco para o Stop Motion, os elementos dos cenários criados e todos os bonecos criados pelas demais disciplinas. As animações seriam roteirizadas e filmadas por um grupo de 3 a 4 alunos que agendariam um horário para o 
desenvolvimento de 10 segundos de animação. A escolha de personagens e de elementos de cenários era livre, como já falando anteriormente. As instruções para os modelos de cenários criados pela turma de cenografia estavam fixadas na parede, cabendo aos alunos de Princípios da Animação optar ou não por usá-las. O que se notou era que os personagens com melhor maleabilidade foram escolhidos e os cenários eram recriados de acordo com a atmosfera criada pela nova história.

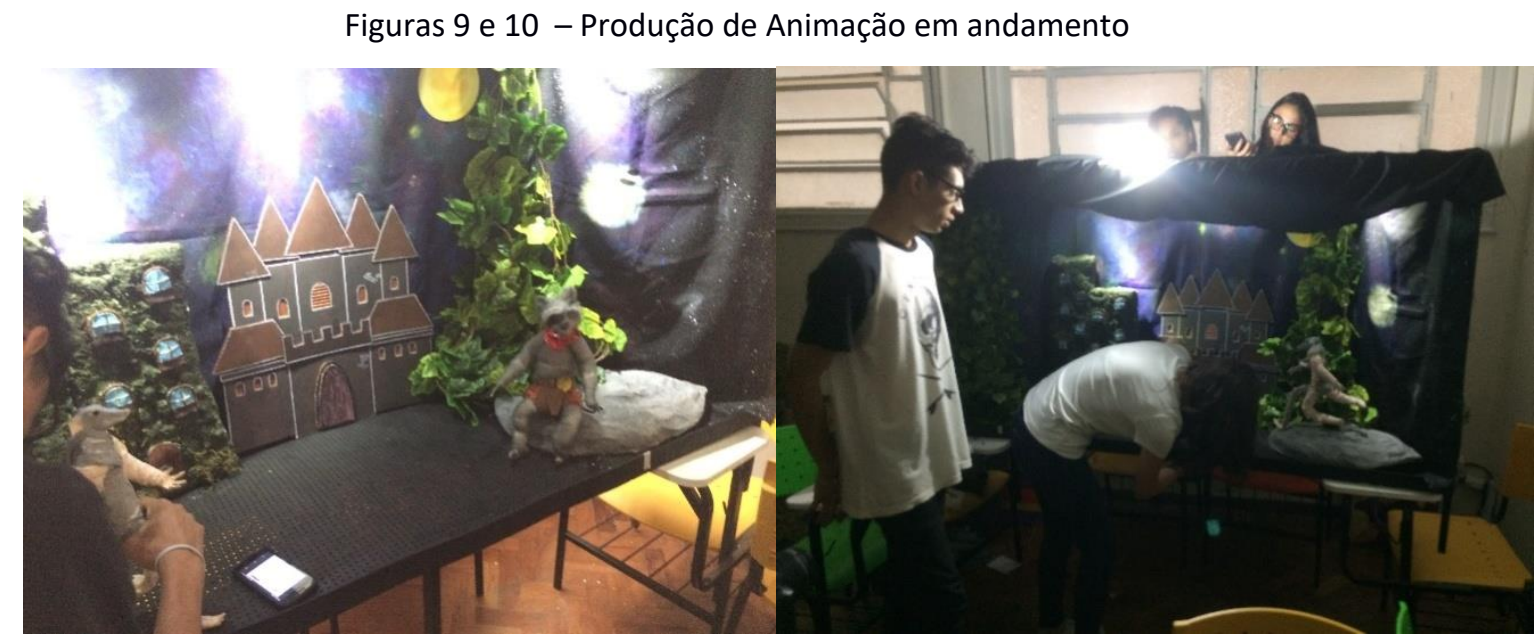

Fonte: os autores

Após fotografar as sequências de imagens, os alunos da disciplina de Princípios, faziam a pósprodução editando, sonorizando as animações para em seguida postar os vídeos em uma pasta compartilhada com todas as disciplinas.

Figura 11 - Exemplo de animação produzida pelos alunos
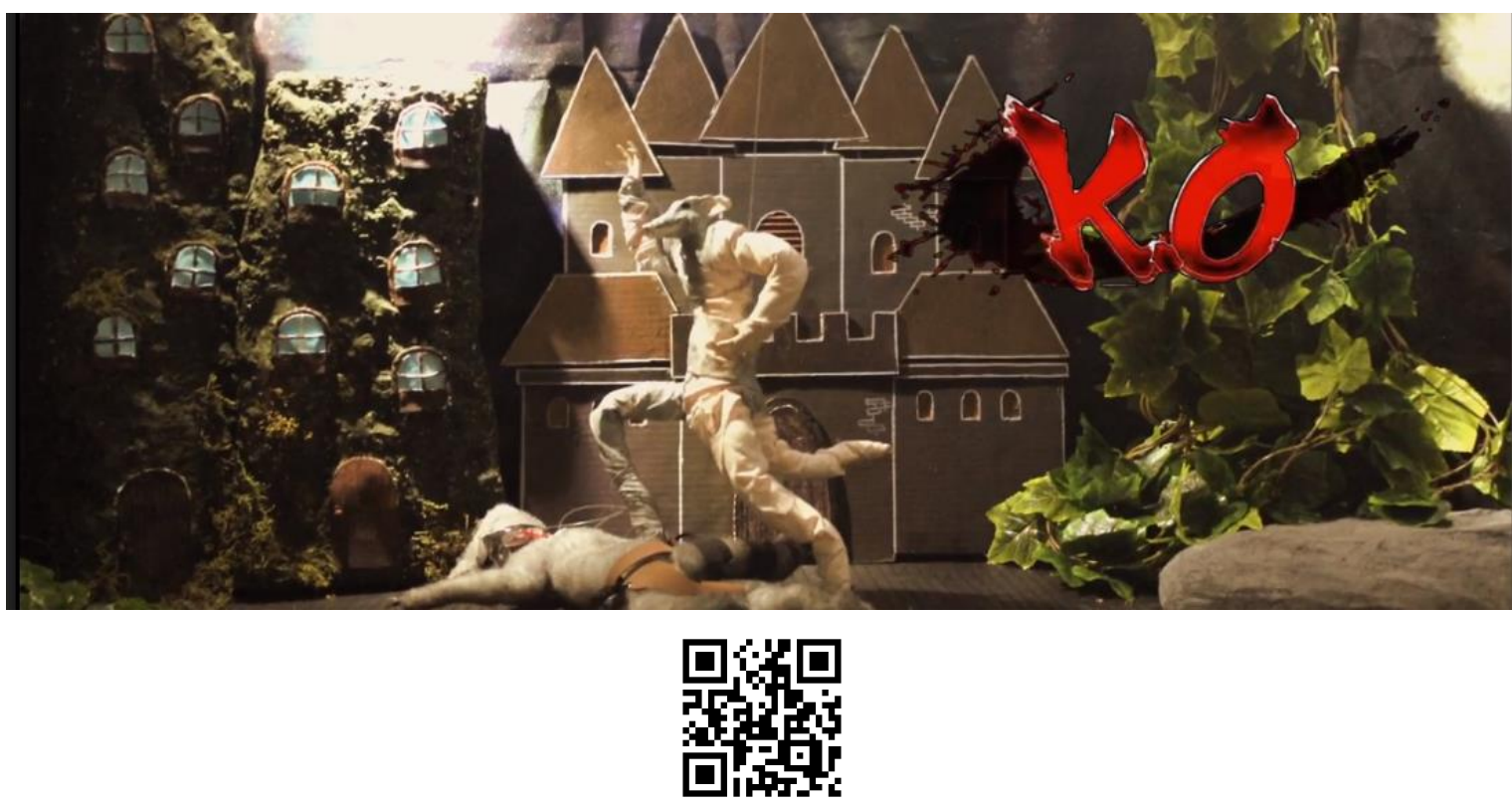

Fonte: os autores (disponível em https://youtu.be/809cEQtktB0 ou Link pelo QR code) 
Figura 12 - Exemplo de animação produzida pelos alunos
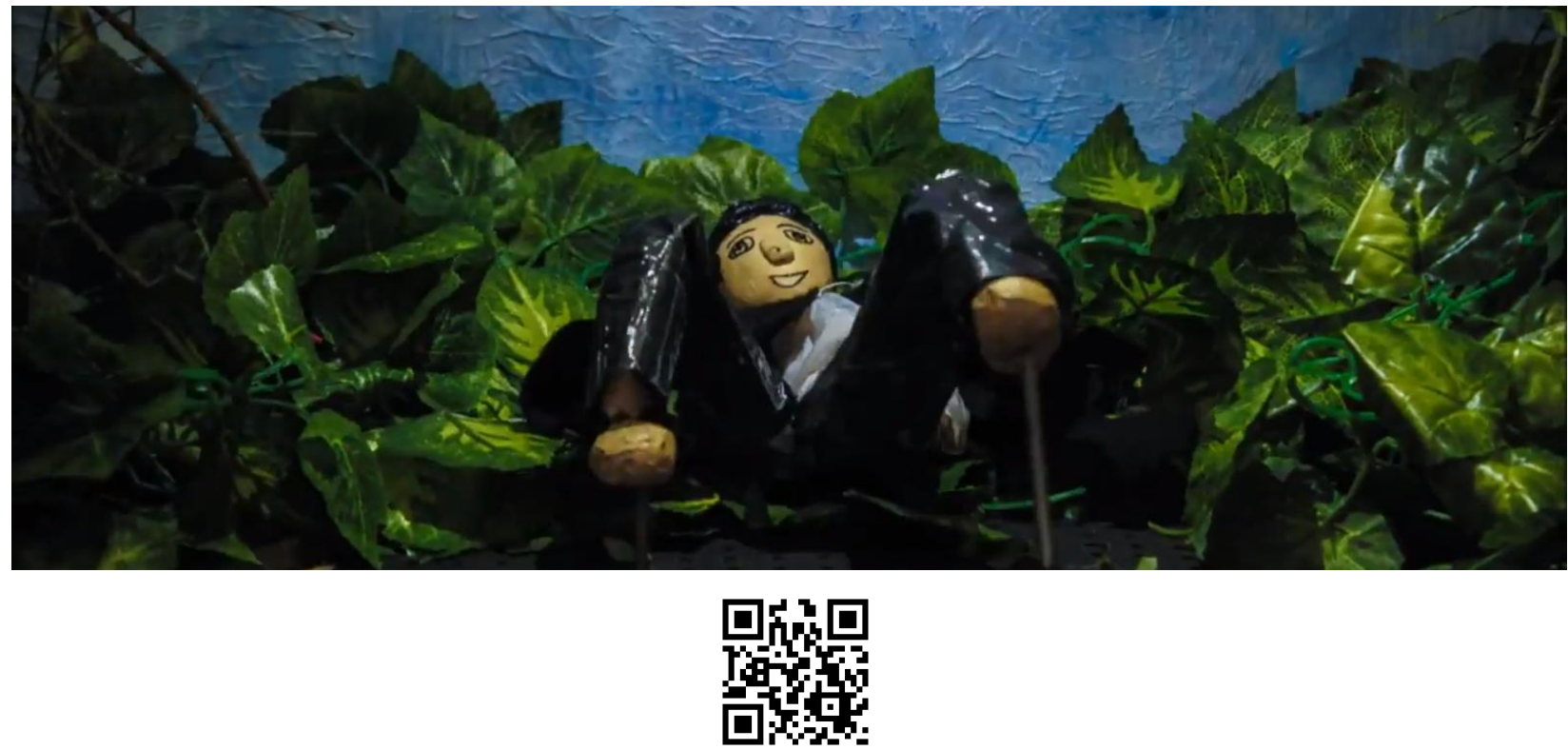

Fonte: os autores (disponível em https://youtu.be/M5HRhKCuoMQ ou Link pelo QR code)

Este método, na verdade, fez com que o processo criativo de cada aluno fosse preservado, e a sua criatividade ainda se faria desenvolver no momento da realização da animação, pois naquele instante eles teriam uma variedade de bonecos, cenários e adereços para criar a sua própria história que deveria ser contada em 10 segundos.

Para facilitar o processo de criação, foi sugerido aos alunos focarem mais em ações do que a criação de histórias complexas (estruturas com 3 atos, apresentação, desenvolvimento, conclusão). Assim, além de focarem na criação de ações com duração mínima de 10 segundos, os alunos também tiveram que superar o desafio de sintetizar uma história com pouco tempo de duração. Para referências, foram convidados a assistir peças publicitárias visando compreender o poder de síntese nesse tipo de produção.

Na prática esta experiência foi importante não só para o desenvolvimento da criatividade de forma bastante livre dos alunos, pois eles não partiam de uma base muito específica, mas também se mostrou um processo de design no momento da filmagem. Para os alunos que foram executar a técnica do Stop Motion, um outro problema era apresentado: eles perceberam que nem todos os bonecos e cenários atendiam às funções necessárias para o roteiro que tinham desenvolvido. Era preciso verificar a funcionalidade dos elementos para a realização das animações. Eles não apenas escolhiam os bonecos e cenários mais interessantes para contar a sua história, mas muitas vezes era necessário adaptar o próprio roteiro aos objetos cenográficos mais funcionais, ou construir um novo cenário a partir dos elementos de cada cenário, apresentando assim novas possibilidades de uso das peças.

O ponto alto de todo este processo foi a preservação da liberdade criadora de cada disciplina, o que permitiu desvincular os elementos (bonecos, figurinos, cenários e adereços) da animação de uma história pré-concebida o que poderia engessar todo o processo, já que estamos falando de um universo de aproximadamente 300 alunos em 4 disciplinas com 9 professores. Não teríamos tempo e nem espaço para coordenar todos se não houvesse uma liberdade na criação de 
cada objeto. O que ainda podemos melhorar principalmente na confecção dos bonecos é na sua técnica construtiva, pois muitos dos bonecos apresentados não funcionaram para a animação em Stop Motion, seja porque não apresentava muita articulação ou o figurino não permitia movimento. Mas já estamos pensando em um workshop em que estas questões técnicas sejam superadas.

O aprendizado para todos, alunos e professores, foi de fato muito rico, para os alunos o pensamento em design se mostrou presente todo o tempo, pois muitas vezes os problemas foram surgindo provocando novas soluções. Para nós, professores, também foi enriquecedor, pois precisamos lidar com os desafios que foram se apresentando tanto no que diz respeito, ao desenvolvimento do projeto em si, mas também no que se refere à articulação das diferentes turmas, nas nossas discussões sobre os próximos passos do projeto e na orientação dos alunos.

\section{Conclusão}

Podemos dizer que foi um exercício para todos, alunos e professores, um exercício interdisciplinar, onde cada um precisou negociar suas delimitações dentro de seus campos de saber em prol de uma realização maior um saber compartilhado. Professores e alunos colaborando de forma horizontal, aprendendo com os desafios, estendendo limites e construindo um consenso através das experimentações e do diálogo.

Para os alunos o conteúdo teórico de cada disciplina foi aplicado ao desenvolvimento do trabalho que era parte de um projeto maior, do qual nem os alunos nem muitos dos professores não tinham conhecimento específico. A animação em Stop Motion proporcionou o alargamento de fronteiras disciplinares característico da interdisciplinaridade. Todos os envolvidos no processo tiveram única e exclusivamente a vontade de realizar um projeto integrado, unindo os três cursos de Design da Universidade. Desta experiência, foram absorvidos alguns aprendizados valiosos para o desenvolvimento de outros projetos interdisciplinares.

Tal exercício mostrou a importância de pensar em mais projetos interdisciplinares. Esta atividade apontou o caminho para a interdisciplinaridade através da comunicação entre os currículos dos respectivos cursos. Numa época em que os currículos tendem a se especializar cada vez mais, se faz necessário trabalhar o ensino de Design focado nas devidas especificidades, porém sem esquecer de enfatizar que o Design é um Campo interdisciplinar por natureza.

\section{Referências}

COUTO, Rita M. S. Escritos sobre Ensino de Design no Brasil. Rio de Janeiro: Rio Book's, 2008.

FONTOURA, Antonio Martiniano. A interdisciplinaridade e o ensino de Design. Projética: Revista Cientifica de Design,V. 2 n.o 2, p. 86-95, dez 2011.

CRUZ, Gabriel F. S. Brinquedos óticos animados e o ensino de Design. 2017.115 f. Tese (doutorado)

- Pontifícia Universidade Católica do Rio de Janeiro, Programa de Pós Graduação em Design. 
MAGALHÃES, Marcos. O tempo do animador. 2015.115 f. Tese (doutorado) - Pontifícia Universidade Católica do Rio de Janeiro, Programa de Pós Graduação em Design.

NICOLESCU, Basarab et al (orgs) Educação e transdisciplinaridade. Tradução de VERO, Judite; Mello, Maria F. de; e SOMMERMAN, Américo. Brasília: UNESCO, 2000 (Edições UNESCO).

DELATTRE, Pierre. Investigações interdisciplinares: objetivos e dificuldades. In: POMBO, Olga; GUIMARAES, Henrique Manuel; LEVY, Teresa. Interdisciplinaridade: antologia. Porto/PT: Campo das Letras, 2006. (Publicação original: Interdisciplinaires (recherches). Objectifs ET difficultés. Encyclopedia Universalis, 1973, p. 387-397)

JAPIASSU, Hilton. MARCONDES, Danilo. Dicionário básico de filosofia. 2 ed. rev. Rio de Janeiro: Zahar, 1993. 